\title{
FRICTION COEFFICIENT OF MUNICIPAL SOLID WASTE COMPONENTS
}

\author{
Yesuenyeagbe A.K. Fiagbe ${ }^{* 1}{ }^{\otimes}$, Emmanuel W. Ramde ${ }^{1}$ \\ ${ }^{* 1}$ Department of Mechanical Engineering, Kwame Nkrumah University of Science and Technology, \\ Kumasi Ghana
}

DOI: https://doi.org/10.29121/ijetmr.v7.i7.2020.702

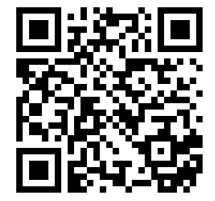

Article Citation: Yesuenyeagbe A.K. Fiagbe, and Emmanuel W. Ramde. (2020). FRICTION COEFFICIENT OF MUNICIPAL SOLID WASTE COMPONENTS. International Journal of Engineering Technologies and Management Research, 7(7), 17.

https://doi.org/10.29121/ijetmr.v7 i7.2020.702

Published Date: 6 July 2020

Keywords:

Municipal Solid Waste

Coefficient of Friction

Waste Components

\section{ABSTRACT}

Engineering properties of materials includes coefficient of friction (COF) which are basic in design performance of engineering systems. The COF can be considered as very important in design of handling tools. Various types of handling tools and equipment are used at various stages of disposal and treatment of MSW and COF is one critical property. This paper presents estimate of COF of municipal solid waste components. The components of the municipal solid waste are paper, plastic, organic and others. The estimation of the COF was done using an inclino-tribometer. Waste from 16 sample locations were used with 6 surfaces which are considered to be of relevant. It was estimated that Formica surface has the least COF values and range from 0.269 and 0.312 with 'others' - formica surface tribosystem being the least. It was also found that paint application on wooden surface with oil paint would increase COF as compared to applying emulsion on same wooden surface. The study pointed out that polishing with vanish is the best way to reduce COF in wood surfaces. It was also observed that painting metal surfaces with oil paint will increase the COF than when the same metal was left unpolished or unpainted.

\section{INTRODUCTION}

Waste generation is of human nature and it is a result of almost all activities. Over the world, in all communities, the management of waste generated, usually refer to as municipal solid waste, has been faced with challenges. It is, however, being managed very well in most developed countries. In developing countries, the challenge is yet to be overcome. The municipal solid waste (MSW) is a complex material and consist of a number of components making it heterogonous. Although waste is heterogeneous, many of the studies show that municipal solid waste has mechanical properties that vary in a consistent and predictable way (e.g. with respect to stress state and method of placement) (Dixon, N. et al, 2005). Most of the properties that are known for various materials usually are of relevant for some purpose. The coefficient of friction (COF) is one of the relevant engineering properties that is used in design. Cho et al (2010) estimated proportional effect of food waste on the COF in the MSW and found that to be directly proportional. The COF becomes very relevant in waste handling and disposal related designs. Friction is generally described as the resistance to motion when two surfaces slide against each other. In most cases friction is a useful phenomenon making many ordinary things like walking and money counting possible. On the other hand friction can also cause undesirable effects which mostly leads to attempt to eliminate it as much as possible. It can therefore be said that frictional effect may or may not be desirable depending on where it exist and function. In solid waste handling and disposal situation, friction may be desirable at a point and undesirable at another point of application.

(C) 2020 The Author(s). This is an open access article distributed under the terms of the Creative Commons Attribution License, which permits unrestricted use, distribution, and reproduction in any medium, provided the original author and source are credited. 
In handling equipment design, one of the important properties of interest is the COF. It is to be noted that coefficient of friction is not a property of the material but that of the tribosystem surfaces in contact and in relative motion. Blau, P.J. (2001) conceptually defined COF as the ratio of two forces acting, perpendicular and parallel to an interface between two bodies under relative motion or impending relative motion. The COF, which is dimensionless quantity turns out to be convenient for depicting the relative ease with which materials slide over one another under particular circumstances. Despite the fact that both static and kinetic friction coefficients can be measured with little difficulty under laboratory conditions, the time- and condition-dependent characteristics of COF associated with both clean and lubricated surfaces have proven exceedingly difficult to predict a priori from first principles.

In specific problems in mechanical design or failure analysis, COF parameters are very important and useful in optimum performance of systems. This paper presents the relative COF of the components of municipal solid waste in respect to some selected surfaces.

\section{MATERIALS AND METHODS}

The forces that resist sliding occur in the regions near and between solid surfaces. The problem of establishing exactly which attributes of the contact conditions and the materials contribute most to the friction force is a major one for developing friction tests and analytical friction models. Models for friction have used geometric arguments (surface roughness and asperity interlocking), mechanical properties-based arguments (shear properties of the solids and of the substances between the surfaces), fluid dynamics approaches, considerations of electrostatic forces between surface atoms, and chemical compatibility arguments (Blau P.J., 2001). Since the number of potential friction-affecting factors is large, it is necessary to identify the set of key variables applicable to each particular case in order to select the appropriate test methods or simulations. If friction tests are more applications-oriented, then the tribosystem of interest must be analyzed and its friction-related variables identified to effect a valid simulation.

Municipal Solid Waste is a complex material and can be difficult to handle. There is therefore the need to characterise the waste by composition. The municipal solid waste was initially characterised and components separated. The characterisation was into six classes, namely: organic, plastic, metal, paper, textile and 'others'. Representative communities were selected such to represent various classes of communities that satisfy all kinds of municipal solid waste generation. The communities were within and around a University. A tribometer was designed and built for the measurement and six different surfaces of interest prepared. The sample areas, tribometer and the surfaces are discussed further in the following sections.

\subsection{SAMPLED AREA}

The type of waste generation varies from community to community based on various factors. These factors include socio-economic status of individuals as well as the community in general, either urban or rural location. The sample areas were in and around a University community. It is observed that the University community is an area made of a cluster of various categories of habitation which can be classified based on the socio-economic status of the residents. The area is segregated into six zones namely Bomso area, Ayeduase area, Faculty area, Halls of residence area, Lecturers' bungalow area and Commercial area. This is done to capture various level of socioeconomic status of the people. The commercial area is where commercial activities including market, shops and banking takes place and the waste generated in this area reflect as such. The faculty area is also where teaching and learning activities happen and the waste generated in this area is paper dominant. The lecturers' bungalows area is of high status community and waste generation within the area reflected and represented that class. The various socio-economic status of the individuals are therefore captured in the sample area. The map of figure 1 shows the indicated localities of choice. 


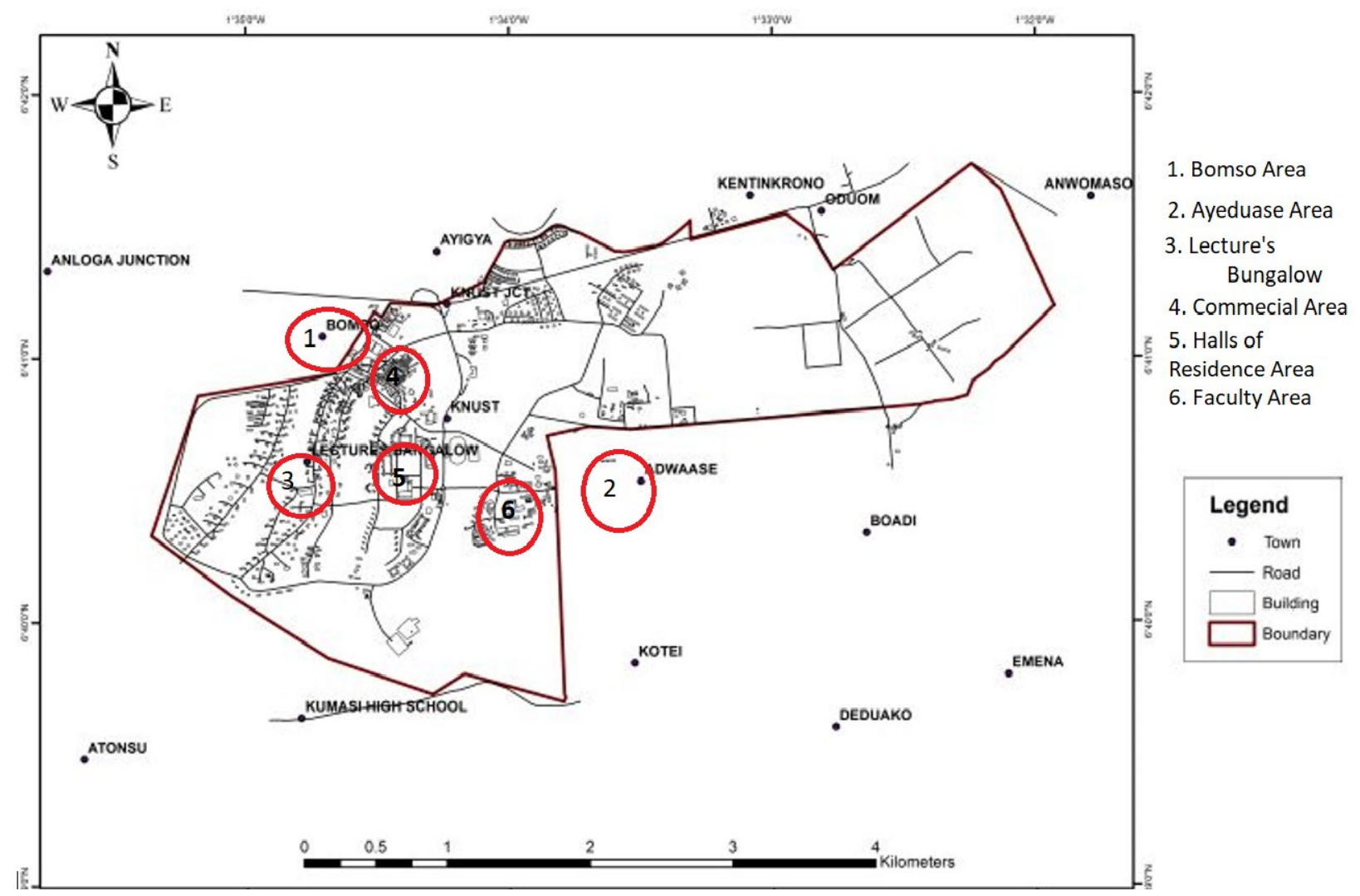

Figure 1: Map showing the sample location within the community.

\subsection{THE TRIBOMETER}

Friction in solid mechanics is the force resisting the relative motion of solid surfaces in contact and sliding against each other. Its effect is usually seen indicated by COF. The COF in general can be said to be a value that indicates the relationship between the force of friction between two surfaces and the normal reaction between the objects that are involved. Old time observations lead to some findings that are summarized in the following three laws: 1 . The force of friction is directly proportional to the applied load (Amontons $1{ }^{\text {st }} \mathrm{Law}$ ) 2 . The force of friction is independent of the apparent area of contact (Amontons $2^{\text {nd }}$ Law) and 3. Kinetic friction is independent of the sliding velocity (Coulomb's Law) (Muser at el, 2001). These laws are however attributed to dry friction only, as it has been well known since ancient times that lubrication modifies the tribological properties significantly.

The first mathematical approach to tribology was undertaken by Leonard Euler (1707-1783) with a geometrical resistance theory of "dry" friction - the Interlocking Asperity Theory. Euler's theory provides two terms for static and dynamic friction. The static friction coefficient is provided by the tangent of the asperity angle, i.e., $\mu=\tan \theta$, while the dynamic friction coefficient is reduced by the kinetic term $2 \mathrm{~s} / \mathrm{gt}^{2} \cos \theta$. The angle is called angle of repose or angle of inclination. The angle of repose between any two surfaces is normally between 0 and 45 degrees and mostly the COF is between 0 and 1 .

If a body is at rest or moving with a constant velocity, it is in equilibrium and the vector sum of all forces acting on the body is zero. It is also true that, if all forces acting on a body are resolved into horizontal and vertical components, the sum of vertical component and sum of horizontal components are the same. From this it follows that if a body is moving with a constant velocity along a horizontal surface in the direction of reaction force, the force of friction is equal and opposite to the reaction force. The force of friction always opposes motion and they are always opposite in direction.

Considering an incline plane as shown in figure 2, the force, $\mathrm{N}$, normal to the plane's surface is equal and opposite to the weight component, $m g \cos \theta$. It is experimentally found that the force of friction $f$, is proportional to the normal component $\mathrm{N}$ of the plane's reaction. 


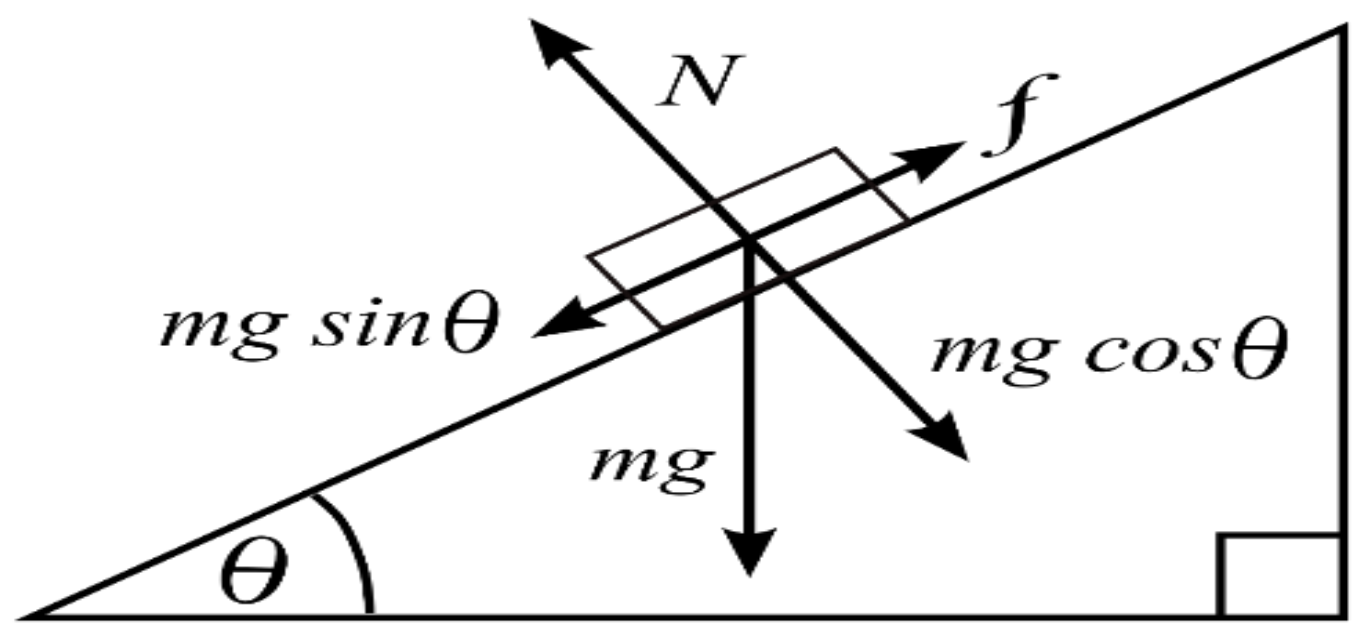

Figure 2: A body moving on an inclined plane

Frictional force, $f=m g \sin \theta$

Also, Frictional Force, $f \alpha N$

Hence: frictional force $f=\mu N=\mu m g \cos \theta$

Therefore: $\quad m g \sin \theta=\mu m g \cos \theta$

This implies that $\mu=\frac{\sin \theta}{\cos \theta}$

$$
\mu=\tan \theta
$$

This lead to the design of inclino-tribometer shown in figure 4 for the estimation of the angle $\theta$.

In friction measurement, equipment that is commonly used is the tribometer. The tribometer is usually designed based on the parameters of interest as well as the materials involve. In this research, an inclino-tribometer was designed for the purpose. The CAD model is illustrated in figure 3 while the manufacturer tribometer is shown in Figure 4. The tribometer consists of an incline plane in which measurable parameter of interest is angle of inclination, $\theta$. It has a lifting screw with handle connected to surface of interest that is hinged to a base with adjustable footing for levelling. The angle of inclination is measured with an electronic protractor that is attached to the surface as well as a build in protractor.
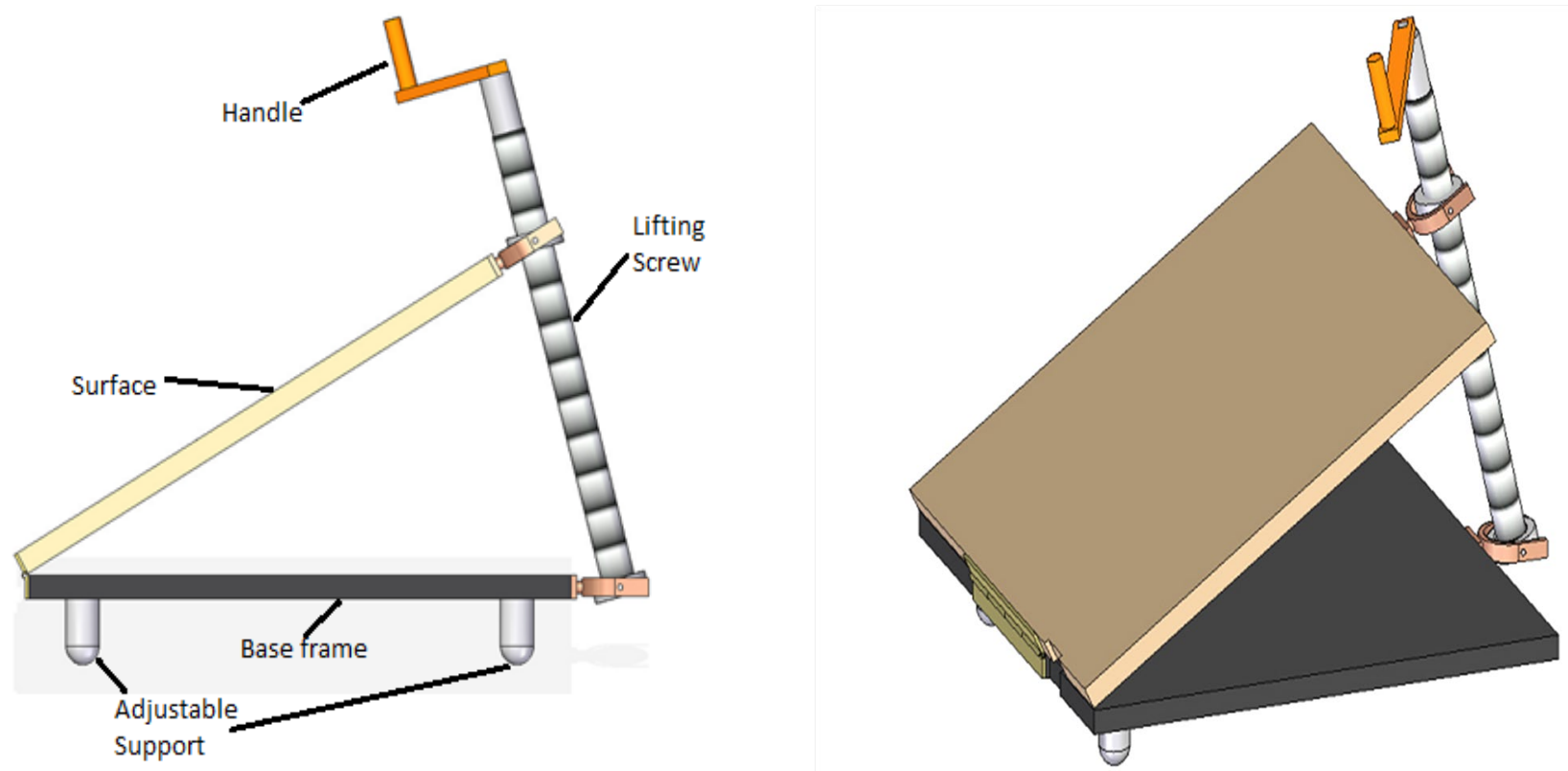

Figure 3: CAD modelled Inclino-Tribometer 

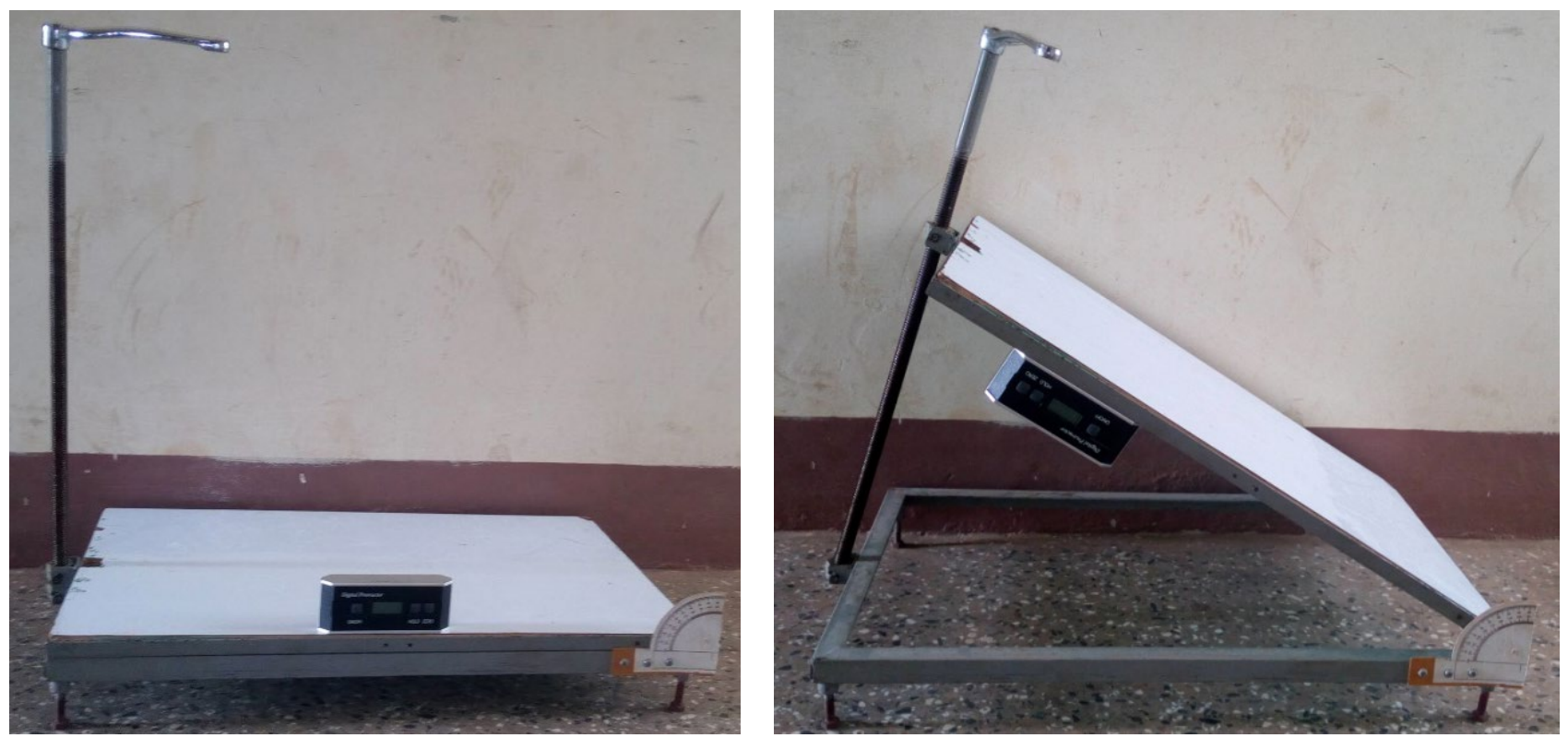

Figure 4: Manufactured Inclino-Tribometer.

\subsection{THE SURFACES}

The research considers six types of surfaces. These are illustrated in figure 5. The surfaces are chosen as they have high possibility of being used in various applications of MSW handling. The surfaces are Formica surface, Emulsion painted Wood surface, Oil paint painted Wood surface, Oil paint painted Metal surface (Steel), Mild Steel metal surface with no paint, Vanish polished Wood surface. These are sized $76.4 \mathrm{~cm} \times 58 \mathrm{~cm}$ to fit the tribometer.
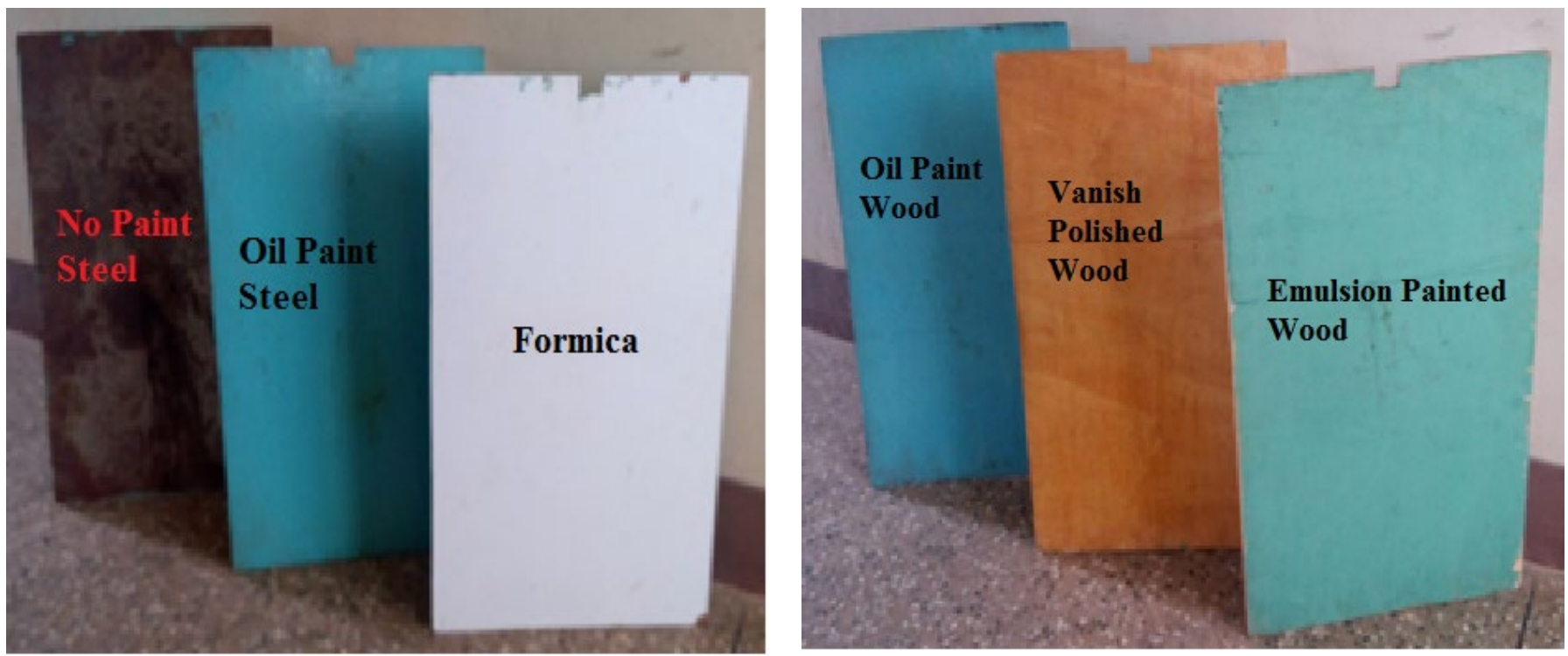

Figure 5: Sample Surfaces prepared for the Experiment.

\section{RESULTS AND DISCUSSIONS}

The data was collected from 6 community groupings. With these localities, 16 locations were sampled and coefficient of frictions were measured for various classes of waste. The classification of the waste are organic, plastic, metal, paper, textile and 'others'. The class 'others' are for the miscellaneous item collections such as glass, sand, etc. The coefficient of friction of the municipal solid waste was measured with respect to various surfaces that were considered to be in possible use in various applications. This means that each waste component and a surface type 
form a tribosystem. Six surfaces were considered and designated appropriately. These surfaces are Formica, S1; Vanish polished wood surface S2; Plain metal surface S3; Emulsion paint painted wood surface S4; Oil paint painted metal surface S5; and oil paint painted wood surface S6. The Formica surface give lowest coefficient of friction with all classes of MSW ranging from 0.269 to 0.3126 . The lower value being for 'others' classified MSW and higher being associated with organic class. The higher range of coefficient of friction is observed to be from 0.72 to 0.886 for oil paint steel surface finished. This is followed by oil paint painted wood surface with value range of 0.65 to 0.83 . The highest value applied to 'others' class. These results are illustrated in figure 6.

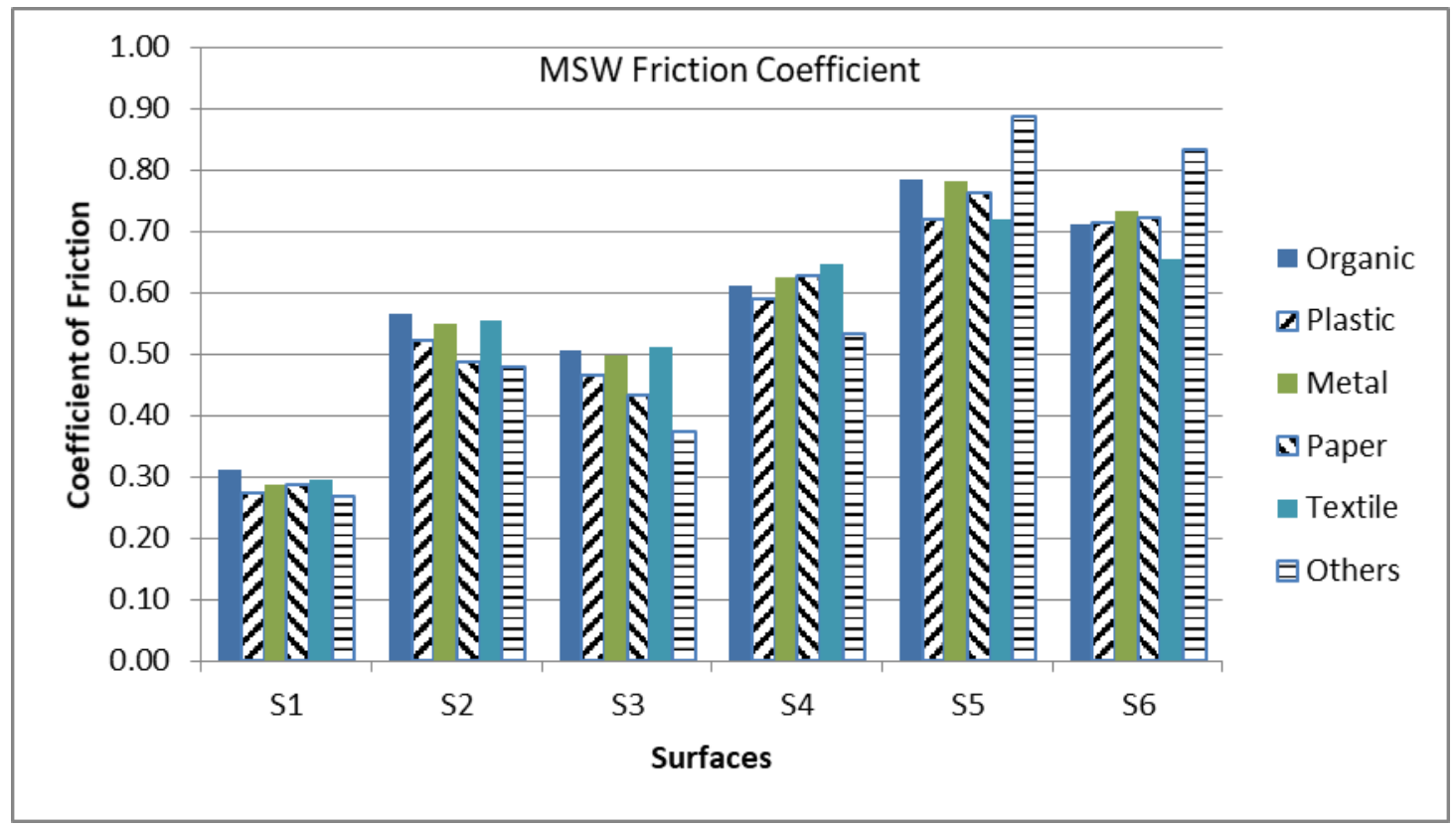

Figure 6: Coefficient of friction with various surfaces.

The standard deviation which indicates the spread of the data value with respect to the mean are such that for the formica surface with organic waste component that resulted in an average value of 0.312 friction coefficient, the standard deviation is 0.0393 ; for vanish polished wood surface with organic waste component with mean friction coefficient value of 0.565 , the standard deviation is 0.0301 . The standard error of 0.0098 is observed with respect to the organic waste-formica surface tribosystem. The standard error of 0.0098 is an indication that the coefficient of friction value of 0.312 for the organic waste-formica surface tribosystem can be accepted as working value. In the case of organic waste - vanish polished wood surface, the standard error of 0.0075 was observed. The highest standard error observed is 0.051 corresponding to 'others' waste - oil paint painted wood surface with a coefficient of friction value of 0.833 .

\section{CONCLUSIONS AND RECOMMENDATIONS}

Handling of municipal solid waste is influenced by frictional effect. The frictional effect can be quantified by the COF which is a property of the tribosystem of interest. Municipal solid waste is a complex and hence segregated into components of organic, plastic, metal, paper, textile and 'others'. The coefficient of friction were estimated based on waste component - surface tribosystem. Generally, the COF is observed to vary from 0.269 to 0.886 . The variation is dependent on the kind of waste component and the surface that make up the tribosystem. The Formica surface gave the least friction resistance with 'others' component class of waste. The highest value is observed for 'others' - oil paint painted metal surface.

\section{SOURCES OF FUNDING}

None. 


\section{CONFLICT OF INTEREST}

None.

\section{ACKNOWLEDGMENT}

None.

\section{REFERENCES}

[1] Blau, Peter J. (2001), the significance and use of the friction coefficient, Tribology International Volume 34, Issue 9, September 2001, Pages 585-591.

[2] Dixon, Neil, Russell, D. and Jones, V. (2005), Engineering properties of municipal solid waste, Geotextiles and Geomembranes Volume 23, Issue 3, June 2005, Pages 205-233.

[3] Van Geffen V. (2009), A study of friction models and friction compensation. DCT 2009.118, Technische Universiteit Eindhoven, Department Mechanical Engineering, Dynamics and Control Technology Group, Eindhoven, December, 2009.

[4] Ludema K.C. (1996), Friction, Wear, Lubrication A Textbook In Tribology, The University of Michigan, Ann Arbor, 1996 CRC Press LLC.

[5] Simple Martin H. Müser, Ludgar Wenning, and Mark O. Robbins (2001), Microscopic Theory of Amontons's Laws for Static Friction, Volume 86, Number 7 Physical Review Letters 12 February 2001 pp 1295 - 1298.

[6] Cho YM ${ }^{1}$, Ko JH, Chi L, Townsend TG. (2010), Food waste impact on municipal solid waste angle of internal friction, Waste Manag. 2011 Jan;31(1):26-32. doi: 10.1016/j.wasman.2010.07.018. Epub 2010 Sep 17. 